\title{
Analysis of the seismic and paraseismic resistance of the VUJE $X=70$ technology base
}

\author{
Martin Ščotka ${ }^{1, *}$, Branislav Valent ${ }^{2}$ \\ ${ }^{1}$ University of Zilina, DSMAM, Univerzitna 1, 01026 Žilina, Slovakia \\ ${ }^{2}$ DOFF s.r.o., Klemensova 16/3,010 01 Žilina, Slovakia
}

\begin{abstract}
Vibration caused by natural seismicity and paraseismicity used in manufacturing facilities can affect the quality of production activity. The vibration velocity of concrete slabs which are impacted by seismic action can be determined by frequency response spectrum. The paper presents a case study of a real industrial assessment.
\end{abstract}

\section{Introduction}

This paper aims to clarify the approach to the assessment of the effects of natural and technical seismicity to high-sensitive machinery parts. Requirements machine manufacturers are now placed on the conditions in which a particular device will work. One of the most important requirements is the aspect of vibration. To determine or to predict conditions with regard to vibration an either FEM (Finite Element Method) simulation or experimental measurements can be used. Simulation FEM calculation model is admittedly less financially complicated, but it requires input (excitation) which is designed as generated and must be defined in frequency or time domain see $[1,2,3]$.

\section{Input data and subject of analysis}

Based on an order from VF, s.r.o. Žilina, in cooperation with experts from this company, the expert analysis of the steel structure "Technology base VUJE X $=70$ " was elaborated. The assessment was processed according to the requirements of the investor as follows: "For a static load from the construction's own gravity and with the defined design response spectra (seismic load) in the horizontal and vertical direction - drawing and 3D model". The weight of components on the steel structure was $530 \mathrm{~kg}$. Their shape and position are defined by the supplied data in the electronic form. The specifications for the power plant calculations are highlighted in red, see document "SE_conditions" [4] and Figure 1.

*Corresponding author: $\underline{\text { scotka1@uniza.sk }}$ 


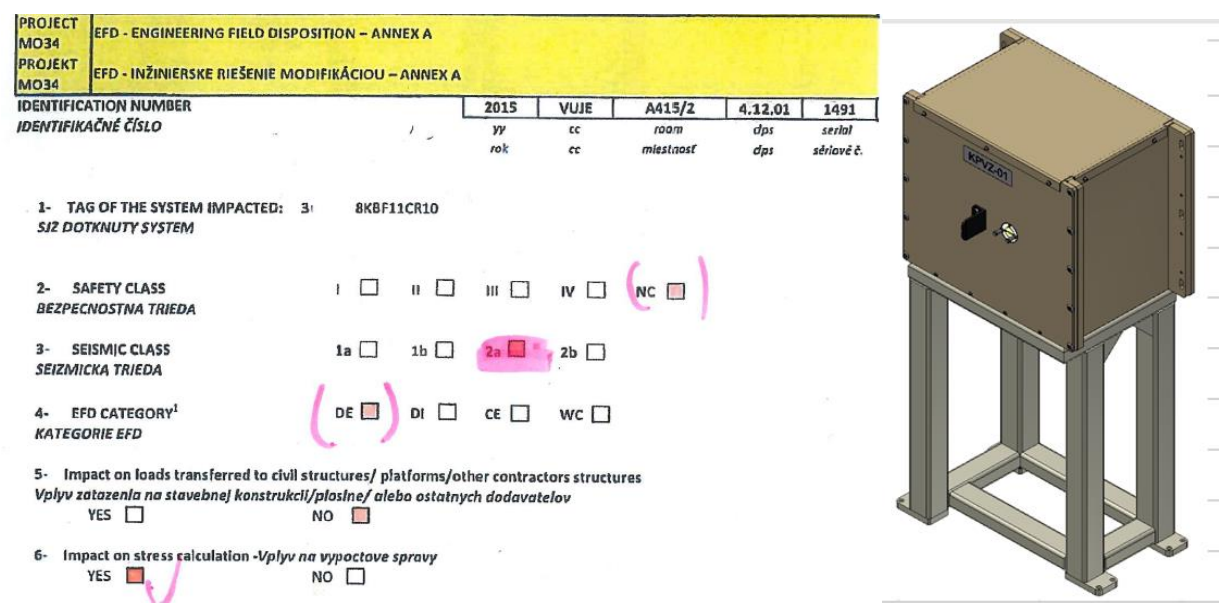

Fig. 1. Internal condition and design of the VUJE $X=70$

\section{Seismic load and dynamic model}

An additional support was made available in the seismic load spectrum from the analysis - "Seismic Resistance of Steel Structure under Shielding - 3D Model" in 2011, developed by MECASYS. In terms of electronic communication with the investor - VF Žilina, the conditions under the "SE_conditions" were observed, when applying the spectrums from the above analysis of seismic resistance. The seismic load was defined based on the values reported in Figure 2. This input was subsequently digitized and the data processed in numerical form. A preview of digitized data for $1 \%$ critical damping is also shown in Figure 2 , in more details in [5].

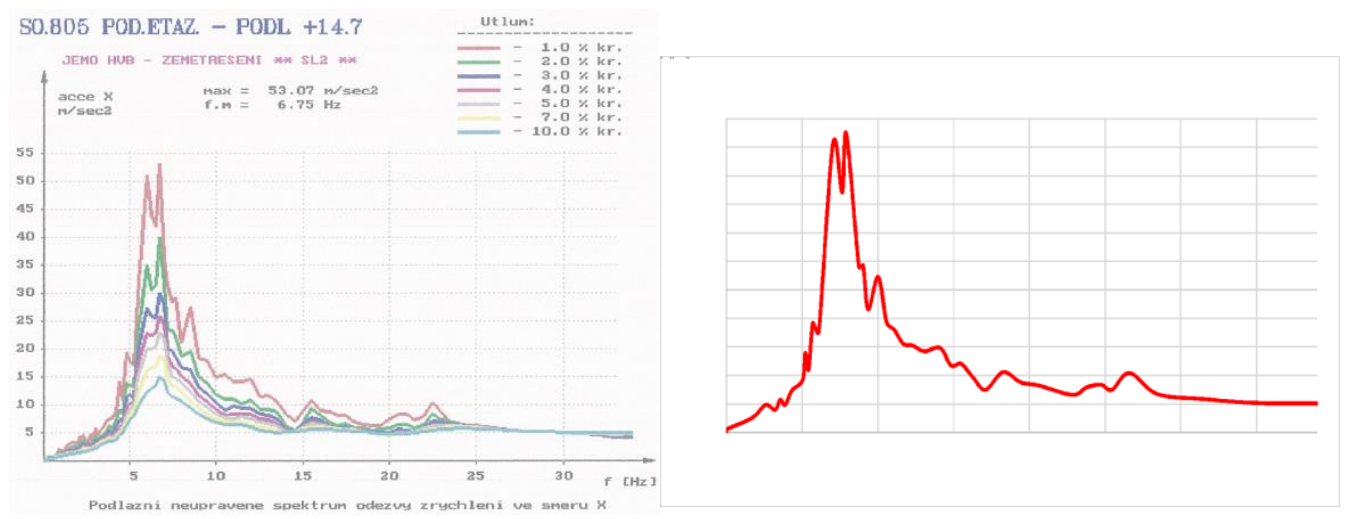

Fig. 2. Calculated and digitalized input acceleration frequency spectrum - seismic dynamic load

Subsequently, a 3D model was created with the FEM (Finite Element Method) method using the AxisVM 13. 0 R 3c computational system. The calculation model takes into account geometric and material parameters, boundary conditions and all other operating conditions in the design layout according to the provided drawing documentation [6]. In the spatial computational model, only reinforcement elements and geometry elements were omitted where we are working on the safe side. The FEM model and the natural frequencies and 
modes of natural vibration are shown in Figure 3.

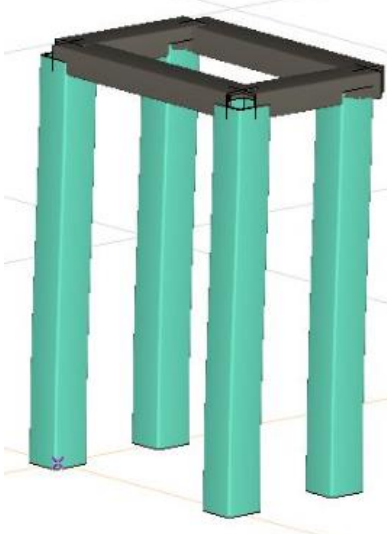

$(24,22 \mathrm{~Hz})$

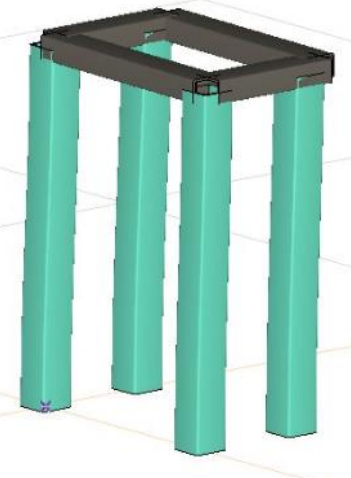

$(27,25 \mathrm{~Hz})$

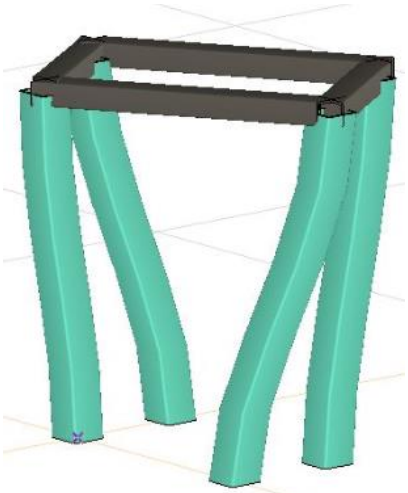

$(226,49 \mathrm{~Hz})$

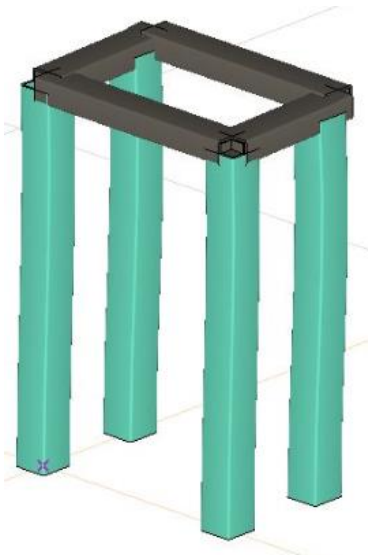

$(230,06 \mathrm{~Hz})$

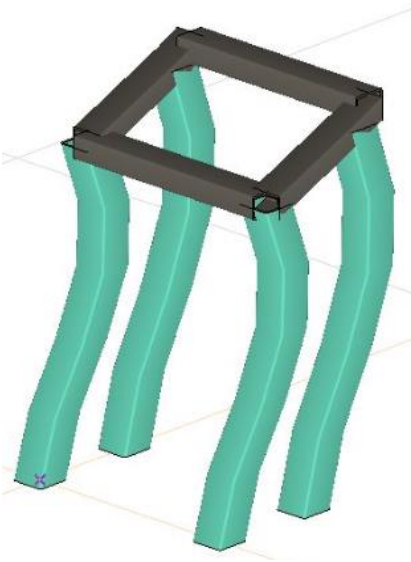

$(588,36 \mathrm{~Hz})$

Fig. 3. The FEM model and the natural frequencies and modes of natural vibration

\section{Conclusion}

The steel structure "VUJE $\mathrm{X}=70$ " was assessed in accordance with the valid legal standards and regulations [7]. The design requirements set by the ordering party were to determine the resistance of the steel structure to the load by its own gravity and the seismic action on the 3D model. The calculation was processed in the AxisVM 13.0 computational system that works on a FEM basis. Axis dynamic calculation and assessment contains detailed review of the individual components drawing the following conclusions:

1. Resistance of the steel structure to the self-weight load and transferred devices load $(530 \mathrm{~kg})$ is expressed by a relative reserve of stability and strength calculation, expressed by the comparison of the real and reduced maximal comparative stress (reduced HMH) in terms of ultimate limit state for steel structures. In this case, the maximum rating at $10.1 \%$ of the cross section utilization and $89.9 \%$ allowance in this limit state. 
2. Resistance of the steel structure to the seismic response spectra load is also expressed by the relative reserve in the stability and strength calculation, expressed by comparing the real and reduced maximum compression (reduced $\mathrm{HMH}$ ) stress in accordance with the ultimate limit state for steel structures. In this limit state, the maximum rating is $14.2 \%$ of the cross section utilization, and $85.8 \%$ allowance in this limit state.

In terms of mechanical resistance and stability of the structure to the loads specified by the customer, the design is designed safely with a sufficient allowance.

This paper was created with the support of the OP Education for the project "Quality education support and research for the transport sector as the engine of the economy" (ITMS: 26110230076), which is cofunded by the European Social Fund.

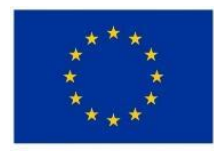

\section{Európska únia}

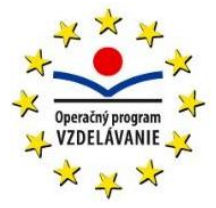

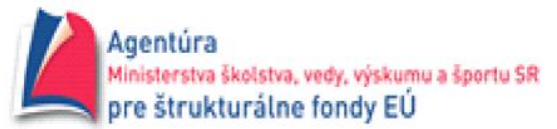

Modern education for knowledge society / The project is co-financed by EU funds.

\section{References}

1. D. Papan, Z. Papanova, Numerical models for the elastic halfspace dynamic response due to road traffic load, MATEC WEB OF CONFERENCES, Volume 251, (2018)

2. L. Figuli, Š. Jangl, D. Papán, Modelling and Testing of Blast Effect On the Structures, Published under licence by IOP Publishing Ltd, IOP Conference Series: Earth and Environmental Science, Volume 44, Issue 5, (2016)

3. D. Papán, Z. Papánová, Spectral Analysis of the Structures due to Traffic, Procedia Engineering, Volume 91, Pages 171-176, ISSN 1877-7058, (2014)

4. EFD - Engineering field disposition - ANNEX A : (2014) ANNUALREPORT, EGPINVEST, Ltd. designing and engineering company, Brno Czech Republic

5. D. Papán, Z. Papánová, Higher frequency dynamic response analysis of the foam concrete block element, MATEC Web Conf. 19601037 (2018)

DOI: $10.1051 /$ matecconf $/ 201819601037$

6. D. Papan, K. Demeterova, The Dynamic FEM Models Results Comparison of the New Bridge Over Danube River in Bratislava, PROCEDIA ENGINEERING, Volume 161,Page 1300-1307, (2016)

7. STN EN 1998-1: (2005) „,Design of structures for earthquake resistance.“ Part 1: General rules, seismic actions and rules for buildings, Bratislava. 